\title{
Teoria crítica em estudos organizacionais no Brasil: o estado da arte
}

\author{
Critical theory in Brazil's organizational studies: the state of art
}

José Henrique de Faria ${ }^{1}$

Toda a produção acadêmica é, necessariamente, o resultado de uma produção coletiva. O autor expressa, de forma organizada e sistematizada, a partir de reflexões e pesquisas, aquilo que foi produzido social e historicamente. Assim, ao escrever na primeira pessoa do singular, procedimento que não costumo adotar, não pretendo negar esse fato, mas apenas assumir inteiramente a responsabilidade pelo texto; ou seja, falo por mim. O que escreverei aqui é a minha avaliação, fruto de mais de 30 anos de estudos e pesquisas nessa área. Por isso, ainda que muitas das concepções sejam originárias de outras reflexões, apenas em casos extremamente necessários, quando a autoria da concepção não for de domínio público, farei referência à bibliografia.

Vou procurar argumentar, neste artigo, que a teoria crítica, entendida como marxismo ocidental, somente agora tem, no Brasil, na área de estudos organizacionais, uma produção sistemática relevante. Ao contrário das crenças fixadas na academia, no Brasil, não houve nessa área de estudos uma linha de pesquisa com substância histórica. Isso não será feito de forma exaustiva, primeiro de tudo, porque não é o propósito dessas reflexões e, em segundo lugar, porque muitas das questões que serão aqui abordadas já foram tratadas em outros textos.

Para facilitar minha exposição, procurarei explorar o tema a partir de quatro questões: Teoria Crítica; Teoria Crítica em Estudos Organizacionais; Critical Management Studies; Análises Críticas em Estudos Organizacionais. É importante considerar que as mesmas não esgotam o conjunto das abordagens necessárias ao esclarecimento do tema do estado da arte da teoria crítica no Brasil, mas oferecem uma boa pista de investigação e um proveitoso motivo para polêmicas, que espero possam ocorrer.

\section{Esclarecimentos iniciais}

Antes de apresentar as questões anunciadas, acredito ser necessário explicitar, a título de esclarecimento, alguns pontos que servem para fundamentar o desenvolvimento da argumentação que se segue. Em linhas gerais, entendo que:

I. existe uma diferença substantiva entre (a) teoria crítica, segundo a tradição da Escola de Frankfurt, (b) teoria crítica em estudos organizacionais (TCEO), que agrega outras dimensões à teoria crítica frankfurtiana, (c) estudos gerenciais críticos, segundo os parâmetros do critical management studies (CMS) e (d) análises críticas em estudos organizacionais (ACEO);

II. a teoria crítica frankfurtiana possui três gerações: a primeira, original, filiada ao marxismo, formada por Pollock, Bloch, Adorno, Horkheimer, Benjamin, Marcuse e Fromm, entre outros; a

\footnotetext{
Pós-Doutorado em Labor Relations pel ILIR - University of Michigan e Doutorado em Administração pela Universidade de São PauloFaculdade de Economia, Administração e Contabilidade da Universidade de São Paulo - FEA/USP. Professor Titular do Programa de Mestrado Interdisciplinar em Organizações e Desenvolvimento da FAE Centro Universitário; Professor Titular Sênior do Programa de Pós Graduação em Educação - PPGE (Mestrado e Doutorado) da UFPR; Pesquisador PO do CNPq; Líder do Grupo de Pesquisa Economia Política do Poder e Estudos Organizacionais. Endereço: Rua Itupava, 1.299 - Sala 103 - Hugo Lange - Curitiba- PR - Brasil - CEP: 80.040-000. E-mail: jhfaria@gmail.com
} 
segunda, liderada por Habermas, que se afasta do marxismo; e a terceira, liderada por Axel Honneth, que se dedica ao estudo da luta pelo reconhecimento na perspectiva crítica hegeliana e habermasiana (inclusive, criticando essas perspectivas). Portanto, falar em teoria crítica frankfurtiana implica identificar também sobre qual das três gerações se fala;

III. a teoria crítica frankfurtiana tem alcance social e é identificada como marxismo ocidental, ou seja, não se vincula ao stalinismo, ao leninismo, ao maoismo e a outros desvios políticos impetrados em nome do marxismo e que resultaram em regimes totalitários, em práticas de autoritarismo, violência, centralismo burocrático e formação de oligarquias, entre outras;

IV. a teoria crítica em estudos organizacionais segue os pressupostos frankfurtianos, mas não se esgota neles. Trata-se de uma teoria que se baseia na dimensão epistemológica do materialismo histórico e no método dialético. Isso significa dizer que a TCEO utiliza-se, ao mesmo tempo, de referenciais do marxismo, das análises frankfurtianas de primeira geração, dos estudos sobre Estado, poder e classes sociais, da psicologia sócio-histórica, da sociologia clínica crítica (ou psicossociologia crítica) e da psicanálise freudiana. A TCEO caracteriza-se por permitir um amplo diálogo com outras teorias, assegurado sua vinculação à dimensão fundante do materialismo histórico. Dada sua dimensão e alcance, bem como sua expressão no campo empírico, tenho identificado, desde 2001, a TCEO como uma economia política do poder em estudos organizacionais (EPPEO);

V. a linha de trabalho identificada por estudos críticos em gestão ou critical management studies, por mais que seus proponentes insistam em referenciar reflexões marxistas, não tem qualquer semelhança ou proximidade com a teoria crítica ou com a TCEO. Trata-se, apenas, de uma linha de usuários eventuais de conceitos marxistas, aos quais faltam metodologia, epistemologia, teoria e ontologia marxistas;

VI. a incorporação do pós-estruturalismo foucaultiano nas análises organizacionais, segundo uma concepção arqueológica, por mais importante que seja (como de fato é), não tem relação com a teoria crítica ou com a TCEO. A tentativa de fazer dos estudos foucaultianos elementos constitutivos da teoria crítica ou da TCEO é um equívoco teórico e epistemológico, ainda que o próprio Foucault, em suas últimas obras, tenha buscado certa aproximação com o marxismo;

VII. a produção acadêmica brasileira que mais se identifica com a teoria crítica na tradição da Escola de Frankfurt é a realizada por Maurício Tragtenberg. Ele foi o precursor e, arrisco afirmar, o fundador da teoria crítica em estudos organizacionais no Brasil, o que se evidencia na publicação de Burocracia e ideologia. Como a direção dada por Tragtenberg aos estudos na área das organizações fixou-se nos referenciais weberianos, marxistas e anarquistas e não teve inspiração em Adorno, Horkheimer, Marcuse, Fromm ou em Habermas, pode-se dizer que Tragtenberg traçou uma linha própria de pensamento e que a proximidade com a teoria crítica não fez dele um intelectual frankfurtiano, mas um estudioso da burocracia, do poder e da dominação, em suas diversas formas de manifestação, pela via do marxismo-anarquismo. É, portanto, com Tragtenberg que foi estabelecida a TCEO como referencial nesse campo de estudos, no Brasil, por meio de uma concepção original. Para diferenciar a teoria crítica da TCEO, segundo a concepção fundada por Tragtenberg, é que, como já afirmei anteriormente, conceituei a TCEO como uma EPPEO;

VIII. a produção acadêmica de Fernando Prestes Motta teve contatos importantes com a teoria crítica, especialmente, com a TCEO. Muitas vezes, no entanto, afastou-se dela ao se aproximar dos estudos sobre a cultura pela perspectiva de Schein e não pela de Walter Benjamin e por buscar inspiração na autogestão proudhoniana (socialismo utópico), não na autogestão social ou no socialismo democrático (socialismo científico). Tal afastamento igualmente decorre do fato de procurar em Jung explicações que não estavam na agenda da concepção pulsional da teoria crítica derivada de Freud (psicossociologia crítica) ou na psicologia social-histórica da Vygotsky. Isso não significa que Motta não possa ser considerado um analista crítico. Ao contrário, para ser justo com Fernando Motta, suas incursões na psicossociologia crítica, no pósestruturalismo de Foucault e nos estudos sobre simbolismo, imaginário e ideologia forneceram 
uma base nova para a análise crítica em estudos organizacionais. Suas tentativas de buscar explicações em outras dimensões teóricas e epistemológicas indicam tanto sua insatisfação com o estado da arte das explicações, quanto sua ousadia em procurar alternativas de análise;

IX. a produção acadêmica de Guerreiro Ramos, ao contrário do que tem sido afirmado alhures, não tem qualquer relação com a teoria crítica. Guerreiro Ramos é um fenomenólogo crítico, não marxista, não frankfurtiano;

X. na atualidade, a TCEO tem encontrado respaldo em algumas linhas de pesquisa, mas outras, que se autodesignam como tributárias da teoria crítica, de fato, não o são, pois não seguem os pressupostos da mesma. Especificamente, chamo a atenção para estudos fenomenológicos, estruturalistas, pós-estruturalistas e da teoria da complexidade de Edgar Morin, entre outros. Não me sinto à vontade para enquadrar esses estudos como teoria crítica quando se utiliza um critério científico de classificação. Proponho, desse modo, que esses estudos sejam considerados uma quarta linha, à qual chamarei de análises críticas em estudos organizacionais.

As quatro grandes áreas dos estudos organizacionais críticos

Com base nas observações precedentes, proponho, esquematicamente, uma organização no campo de estudos organizacionais críticos em quatro grandes áreas:

I. teoria crítica frankfurtiana - que se baseia em estudos sociais e segue as orientações teóricas e filosóficas da Escola de Frankfurt, independentemente de qual seja a geração a que se filia;

II. teoria crítica em estudos organizacionais - que se baseia no marxismo em seus estudos e pesquisas no campo das organizações, com ênfase na centralidade do trabalho (processo e relações de trabalho, divisão do trabalho e gestão do processo de trabalho), contemplando, além dos estudos frankfurtianos, outras dimensões, tais como a psicologia sócio-histórica, a psicossociologia crítica, as formas democráticas de gestão (autogestão social e organizações coletivistas de trabalho), as análises sobre Estado, poder e classes sociais etc., área essa à qual denomino "economia política do poder em estudos organizacionais";

III. critical management studies - que se baseia em estudos críticos em gestão na perspectiva da gestão, cuja referência encontra-se nos estudos conduzidos principalmente por Alvesson, Deetz e Willmott;

IV. análise crítica em estudos organizacionais - que se baseia em estudos segundo novas dimensões, como o pós-estruturalismo de Foucault, o pós-modernismo de Lyotard, as análises institucionais de Lourau e Lapassade, o simbolismo de Bourdieu, o imaginário de Castoriadis e a teoria da complexidade de Morin, entre outros. São análises críticas não marxistas e não frankfurtianas que estudam as organizações, do ponto de vista das relações de poder.

Adiante, a figura 1 resume o esquema proposto.

Vou me ocupar, a seguir, da teoria crítica frankfurtiana e sua relação com a TCEO e as ACEO, pois os CMS estão bem definidos na literatura e sobre eles já disse o que havia para dizer. De fato, indicadas essas quatro áreas - que constituem, em minha concepção, a matriz do que se pode chamar genericamente de estudos organizacionais críticos -, convém analisar os fundamentos da teoria crítica e sua apropriação pela área. Começo lembrando que no campo dos estudos organizacionais, a teoria crítica ainda tem sido identificada como simples crítica teórica ou como abordagem crítica que articula uma crítica à teoria das organizações, embora permaneça prisioneira dos fundamentos epistêmicos desta. Essa inadequação tem permitido classificar como teoria crítica textos que não se enquadram em seus pressupostos epistemológicos e metodológicos, o que sugere ser necessário demarcar o alcance dessa teoria nos estudos organizacionais, desvinculando-a da mera crítica teórica e dos estudos críticos em gestão. 


\section{Figura 1 \\ Áreas de estudos organizacionais críticos}

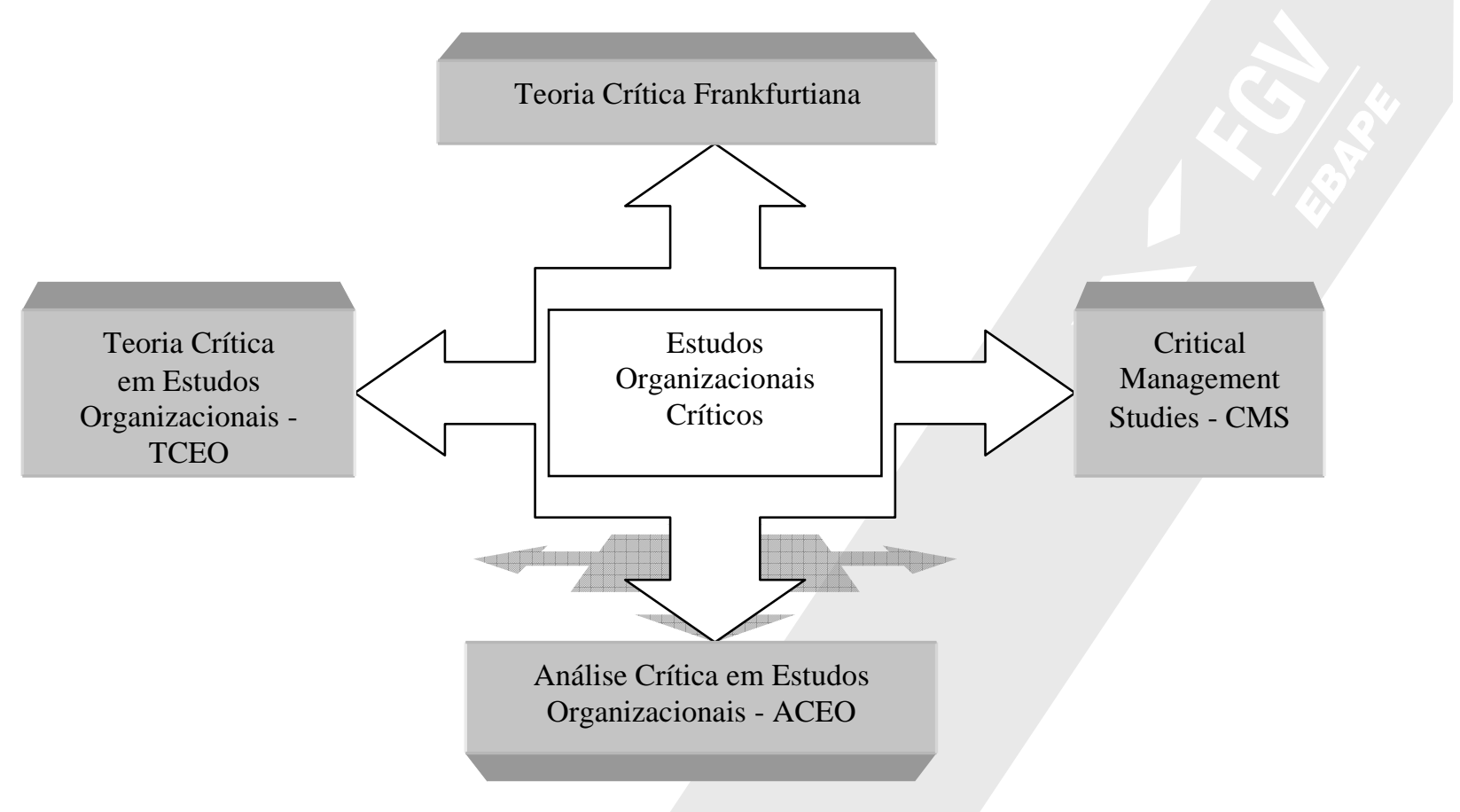

Fonte: Elaborada pelo Autor

Horkheimer já sugeria encorajar a elaboração de uma teoria da sociedade em sua totalidade, que fosse precisamente crítica e dialética, de forma a fazer emergir as contradições da sociedade capitalista. Desse modo, caberia à teoria crítica, como indicou Adorno, investir contra as imagens deformadas da realidade que desenvolvem a função de servir ao poder, não dando voz à realidade desordenada do capitalismo. Assim, ao denunciar o eclipse da razão, Horkheimer afirmava que por detrás da pura lei econômica, da lei do mercado e do lucro encontrava-se a pura lei do poder de uma minoria, baseada na posse dos instrumentos materiais de produção, de forma que a tendência ao lucro acabava sendo o que sempre foi, ou seja, a tendência ao poder social. No âmbito do estatismo de inspiração soviética, o lucro foi substituído pelo plano, mas as pessoas continuaram objetos de uma administração centralizada e burocrática: tanto os controles sobre o lucro como os controles sobre o plano geraram formas cada vez mais agudas de repressão. É nesse sentido que argumentei já em 2001 que a teoria crítica se constituía não somente em uma teoria da economia, mas do poder: uma economia política do poder. Aplicada à área das pesquisas em organizações, a teoria crítica constitui uma economia política do poder em estudos organizacionais.

\section{A teoria crítica e a economia política do poder em estudos organizacionais}

No sentido anteriormente exposto, os estudos sobre a vida nas organizações que se apoiam na teoria crítica devem investigar mais do que as racionalidades instrumentais, que as estratégias, que as funções, que as instituições, que os comportamentos e que as políticas. Devem desvendar o mundo do poder e as formas de controle econômico, jurídico-político, ideológico e psicossocial sobre o processo e a divisão do trabalho para se sentirem autorizados a compreender as organizações e suas finalidades. A TCEO, na ótica da economia política do poder, indica que a compreensão da vida nas organizações e sua dinâmica exigem a adoção de uma epistemologia apoiada no materialismo histórico e de um esquema teórico-metodológico dialético capazes de responder às questões que afetam a vida cotidiana dos sujeitos coletivos das mais variadas formas e que valorizem esse sujeito coletivo mais do que as organizações para as quais vendem sua força de trabalho.

As organizações são, de fato, construções sociais e históricas que adquirem autonomia relativa em relação aos sujeitos coletivos que a constituíram e que se consolidam como instâncias de mediação entre os interesses dos 
sujeitos a ela vinculados e os objetivos para os quais foram criadas. As organizações não são entes abstratos, sujeitos absolutos, entidades plenamente autônomas, unidades totalizadoras e independentes, mas construções sociais dinâmicas e contraditórias, nas quais convivem estruturas objetivas e subjetivas, manifestas e ocultas, concretas e imaginárias, cabendo à TCEO a atribuição política de investigá-las além de seu aspecto fenomênico. Como afirma Kosik, é preciso, mais do que a coisa, conhecer a estrutura da coisa.

O problema central de uma teoria crítica, portanto, consiste em esclarecer em que medida as instâncias obscuras (que se operam nos bastidores organizacionais, nas relações subjetivas e no inconsciente individual) e manifestas (especialmente, as referentes ao regramento e às estruturas formais) dão conteúdo às configurações do poder nas organizações do ponto de vista do sujeito coletivo do trabalho. É preciso revelar em que medida as organizações definem seus mecanismos de poder e de controle sobre o processo e as relações de trabalho, incorporando o que não pode ser dito, que se reproduz em seus porões, ao que é possível falar, ao que pode ser manifesto às claras, de maneira a criar um mundo ao mesmo tempo de racionalidades (de regras, objetivos, políticas, processos produtivos, planos, estratégias etc.) e de (inter)subjetividades (símbolos, ritos, imaginários e mitos), com seus paradoxos e contradições.

A TCEO não é completa e definitiva, mas precisa assumir seu compromisso histórico com a denúncia da repressão, do controle e da exploração, baseada na convicção de que uma sociedade igualitária é a única alternativa para que se estabeleçam os fundamentos da justiça, da liberdade e da democracia. Portanto, cabe à TCEO desenvolver formulações que expliquem o real em sua forma e em sua substância, que permitam compreender além do que pode ser visto e imediatamente entendido pela sociedade. A TCEO constitui-se, assim, a partir das análises do materialismo histórico e do método dialético, para apreender os processos de transformação que se operam no modo de produção para estabelecer as relações entre os sujeitos da ação e a própria ação. Desse modo, TCEO não pode se contentar com as análises que se encerram no plano da macrossociedade e tampouco com as que pretendem explicar o mundo a partir do sujeito individual (do comportamento, da cognição, do conhecimento, da liderança e de outros atributos pessoais), reclamando a construção de uma epistemologia que possa tratar de ambas as representações.

Por não servir aos interesses dominantes no campo teórico da análise organizacional, a TCEO tem sido classificada como radical, em seu sentido pejorativo. Porém, ao examinar a ética e a moral da sociedade, ao interrogar as práticas sociais, ao questionar as relações de poder, ao investigar as formas de controle social, ao revelar a psicodinâmica do trabalho, ao trazer à tona a constituição do processo de trabalho sob o capital e as formas de exploração aí encontradas, a TCEO é de fato radical, no sentido de que pretende ir à raiz dos problemas, de que não se satisfaz com o que é dado pelas constatações resultantes das pesquisas, de que não lhe basta compreender a forma sem o conteúdo e a aparência sem a essência. O pensamento radical é a busca incessante das contradições sociais, em que a realidade aparente passa a ser questionada e torna-se objeto de investigação.

Sem embargo, o que se deve buscar no estudo das organizações são as relações internas e externas de poder, manifestas tanto em suas formas de controle e em sua ação mediadora de objetivos e desejos, quanto em sua inserção dinâmica e contraditória na sociedade globalizada. As relações de poder têm como finalidade a posse política, o domínio das estruturas organizadas da sociedade, daí a razão de se falar em uma economia política do poder, pois se trata de compreender, ao mesmo tempo: (i) a interação entre o movimento da sociedade, do ponto de vista do modo de produção, e do Estado capitalista contemporâneo e (ii) as lógicas internas da dinâmica organizacional. Essa interação é necessariamente contraditória, paradoxal e, jamais, definitiva. A análise deve estar fundamentada no entendimento das relações entre os sujeitos coletivos, seja no campo do trabalho, da produção, da realização, do imaginário ou dos afetos, em seus aspectos objetivos e subjetivos; ou seja, nas relações de poder.

A economia política do poder é, portanto, a forma que assume a teoria crítica, fundada no materialismo histórico marxista, no método dialético e na interdisciplinaridade. No campo das organizações, a EPPEO leva em conta tanto os movimentos internos e contraditórios destas (nos quais se contemplam as realidades manifestas e ocultas, compartilhadas ou não pelos sujeitos), como suas interações com a totalidade social (interações igualmente complexas e contraditórias), nas quais se contempla o sociometabolismo do capital, conforme conceitua István Mészáros. As organizações, como unidades de análise, não podem ser tomadas 
independentemente, tanto do lugar que ocupam nas relações de produção e na ampla superestrutura social, quanto das relações objetivas e subjetivas que se estabelecem no interior da mesma.

Entretanto, é necessário colocar com clareza que há uma importante diferença epistemológica, com consequências teóricas e metodológicas, entre estudar as organizações a partir das suas interações contraditórias com a totalidade social e estudá-las a partir dos efeitos do ambiente externo sobre a realidade interna e dos efeitos da realidade interna sobre o ambiente. Para a EPPEO, não se trata de estudar os efeitos, sejam quais forem as direções destes, mas as relações, e não apenas as relações presentes nas estruturas e que as constituem, mas as relações dialéticas: essa diferença marca profundamente o campo da TCEO/EPPEO e da teoria crítica frankfurtiana, distinguindo-as tanto das ACEO - que se fundamentam no estruturalismo, no pós-estruturalismo (inclusive, o foucaultiano), na fenomenologia crítica, no pós-modernismo, no estruturacionismo e na teoria da complexidade -, quanto dos estudos críticos em gestão (CMS), que se fundamentam na teoria institucional clássica, no funcionalismo, no positivismo, na teoria dos sistemas, na metafísica (neo)kantiana, no pragmatismo e no empirismo, ainda que sejam usuários de conceitos neomarxistas e foucaultianos, entre outros.

\section{A teoria crítica em estudos organizacionais no Brasil: o estado da arte}

No Brasil, a adoção da teoria crítica em estudos organizacionais foi magistralmente realizada por Maurício Tragtenberg no início dos anos 1970. Em Burocracia e ideologia, seu mais conhecido trabalho, Tragtenberg ousa um pensamento interdisciplinar e lança as bases de uma verdadeira transformação nesse campo de estudos, no qual se evidencia um fundamento de importância nuclear: o que marca a TCEO é a coerência epistemológica.

A questão posta por Maurício Tragtenberg é a do poder e, assim, a da recusa a toda a forma de dominação, a crítica à violência, a denúncia ao burocratismo, o apontamento à ideologia gerencialista que predomina na chamada teoria geral da administração e, ao mesmo tempo, a defesa intransigente da democracia e do projeto libertário. São os estudos de Tragtenberg que inspiraram Fernando Prestes Motta, Fernando Coutinho Garcia e a mim, como o próprio Maurício indica em seu memorial, a levar adiante essas investigações no campo organizacional.

Cabe à teoria crítica questionar a si mesma, fazer uma teoria crítica de si e se perguntar: quais suas perspectivas diante do capitalismo contemporâneo do terceiro milênio, em que as relações de poder se tornam cada vez mais sofisticadas, em que o imperialismo se autointitula globalização, em que as condições de vida da classe trabalhadora se deterioram diante de uma reestruturação produtiva do capitalismo, em que profetas recém-saídos do forno anunciam a impossibilidade concreta de um socialismo democrático, em que novos filósofos desacreditam das grandes teorias e se contentam com explicações particulares sem projetos?

Os que postulam por transformações radicais sempre constituíram uma minoria no mundo dos estudos organizacionais, mas nem por isso deixaram de produzir suas críticas. Atualmente, no Brasil, os pesquisadores ligados à teoria crítica propriamente dita, à teoria crítica em estudos organizacionais e às análises críticas em estudos organizacionais já formam um grupo bem mais consistente do que o que havia nas décadas de $1970 \mathrm{e}$ 1980, quando Tragtenberg dá impulso a essa área. Não se pode dizer que seus componentes têm a mesma orientação teórica, mas possuem grande proximidade. Refiro-me, apenas a título de ilustração, aos grupos atuantes nas universidades federais do Rio Grande do Sul (UFRGS), de Santa Catarina (UFSC), do Paraná (UFPR), de Minas Gerais (UFMG), do Espírito Santo (UFES) e de Pernambuco (UFPE), na Universidade de Brasília (UnB) e na FGV (São Paulo e Rio de Janeiro), entre outras instituições de ensino. Apesar da existência desses grupos e do fato dos pesquisadores que os compõem terem algum grau de proximidade de interesses, não existe uma rede acadêmica de teoria e análises críticas no Brasil, o que promove a contenção dos avanços nessa área de investigação. $\mathrm{O}$ estabelecimento de uma rede acadêmica de teoria e análises críticas é, na minha avaliação, necessária e urgente.

Ao mesmo tempo, entendo que a linha dos critical management studies constitui-se como a crítica não crítica de estudos críticos. Trata-se de uma abordagem na qual o papel da crítica não tem um caráter revolucionário, mas reformador. Não estou, com isso, pretendendo significar que esses estudos sejam inúteis, inadequados, inapropriados etc. Apenas, não considero essa linha parte da teoria crítica ou das análises críticas, porque não 
partilha de seus fundamentos. Os CMS têm seu lugar no campo organizacional, têm seguidores e adeptos de renome e apresentam interessantes contribuições. Entretanto por uma questão de coerência, não se pode considerá-los vinculados à teoria crítica ou às análises críticas.

Procurei, nessas reflexões, explicitar minha avaliação quanto ao estado da arte da teoria crítica no Brasil na área de estudos organizacionais. Para tanto, procurei distinguir as várias formas que assumem as vertentes da teoria crítica e, em seguida, propus um esquema no qual classifico os estudos organizacionais críticos em quatro grandes áreas: (i) teoria crítica, segundo a tradição da Escola de Frankfurt; (ii) teoria crítica em estudos organizacionais; (iii) critical management studies ou estudos gerenciais críticos; e (iv) análises críticas em estudos organizacionais. As duas primeiras áreas constituem a teoria crítica, e embora não comunguem da mesma linha teórica e epistemológica que a das análises críticas, entendo que possam dialogar. Os CMS, contudo, pertencem à outra face da matriz dos estudos organizacionais críticos.

Embora seja uma área ainda incipiente, a mesma vem aparecendo com cada vez mais força e consistência nos Enanpads e nos Eneos. Novos pesquisadores, mestrandos, mestres, doutorandos e recém-doutores estão se incorporando à área, graças ao esforço dos orientadores nos programas de mestrado e doutorado e aos seus projetos de pesquisa, o que cria uma expectativa de que, embora em minoria, os grupos atuantes em teoria e análises críticas continuarão resistindo e apostando na transformação do status quo. Daí que a formação de uma rede acadêmica de teoria e análises críticas, composta por pesquisadores e programas, torna-se estrategicamente fundamental para o fortalecimento e a continuidade da área. 